\title{
Nuevas Experiencias en la Exportación de Papa: El Caso de la Papa Amarilla Peruana
}

\author{
Miguel Ordinola ${ }^{1}$
}

\begin{abstract}
Resumen
Este trabajo documenta las actividades relacionadas con los intentos de penetrar y establecer un mercado en los Estados Unidos para papa procesada producida y transformada en el Perú. Se incluye una breve discusión del origen de dicho programa piloto; los esfuerzos para atender una demanda latente para productos ecológicos y de alto valor nutricional en los estados de Florida, New Jersey, y New York; las cadenas de oferta dentro el Perú y los Estados Unidos; y los costos de producción y venta del producto. En las conclusiones, se presenta una serie de resultados además de una lista de lecciones útiles para ellos contemplando intentos similares en el futuro.
\end{abstract}

\section{Introducción}

Con la liberalización de la economía Peruana a partir de 1990, se incentiva el comercio exterior de algunos bienes y servicios. Productos agrícolas como ajos, cebolla, espárrago, frutas, fibras y otros comienzan a orientarse al mercado internacional. Pero el efecto más importante está en los alimentos agrícolas procesados, especialmente precocidos y congelados, que generan cadenas hacia adelante y hacia atrás resultantes de su exportación. Entre estos productos, la papa amarilla surge como una alternativa interesante por las ventajas comparativas de exclusividad y calidad que posee el Perú.

Dentro de este contexto, el presente documento analiza las experiencias recientes de un programa piloto de promoción de la exportación de papa amarilla a los Estados Unidos con el objetivo de: (1) describir el contexto y la estrategia que dieron inicio a dichas actividades, (2) sistematizar los logros del programa en su fase inicial, y (3) obtener lecciones de dichas experiencias para acciones futuras.

\section{Evolución de las exportaciones de papa procesada en el Perú}

Las actividades de promoción de la exportación de papa amarilla procesada se han dado dentro de un escenario de apertura de la

1 Economista, Gerente de Mercadeo, Programa de Desarrollo Alternativo -Consorcio CARE-Chemonics International Inc - Planning Assistance. Lima-Perú.

Correo electrónico: ordinola@carepe.org.pe 
economía Peruana. Históricamente, Perú ha sido un país con diversos productos agrícolas para la exportación incluyendo caña de azúcar, algodón, harina de pescado, y café entre otros. Sin embargo, el sector papa ha sido una excepción. La producción nacional siempre ha sido casi exclusivamente para el consumo interno (Scott, 1986, 1998). No obstante, con la nueva política de apertura en 1990, el país empezó a buscar mercados para nuevos productos de exportación notradicionales. Así, empresarios nacionales privados buscaron aprovechar las ventajas comparativas de oportunidad, calidad y exclusividad que tiene el Perú en la producción de productos agrícolas incluyendo la papa.

El rubro de exportaciones de papa de mayor importancia en el periodo 1993-97 fue el de papas cortadas en trozos 0 en rodajas, secas. Analizando las cifras del Cuadro 1, las exportaciones de papas cortadas en trozos o en rodajas, secas, han ido perdiendo mercado año a año, exceptuando 1994, cuando sólo Japón importó $62 \%$ (54 t) del producto total, aproximadamente nueve veces más que en 1996. Los principales países importadores fueron Japón con el 45\% y Estados Unidos con el $37 \%$ de la compra total.

\section{Cuadro 1. Exportaciones de papa procesada (kg netos) del Perú,} 1993-97

\begin{tabular}{|ccccccc|}
\hline Años & $\begin{array}{c}\text { Preparada } \\
\text { o en } \\
\text { conserva1 }\end{array}$ & $\begin{array}{c}\text { Cortadas } \\
\text { en trozos o } \\
\text { rodajas } \\
\text { secas }\end{array}$ & $\begin{array}{c}\text { Harina, } \\
\text { fécula y } \\
\text { copos de } \\
\text { papa }\end{array}$ & $\begin{array}{c}\text { Precocidas } \\
\text { congeladas }\end{array}$ & $\begin{array}{c}\text { Conge- } \\
\text { ladas }\end{array}$ & $\begin{array}{c}\text { Total } \\
\text { exps. }\end{array}$ \\
\hline 1993 & 0 & 44,815 & 27,814 & 0 & 80,810 & 153,439 \\
1994 & 1,428 & 86,984 & 39,507 & 589 & 0 & 128,508 \\
1995 & 3,257 & 34,010 & 31,353 & 32,084 & 0 & 100,704 \\
1996 & 3,626 & 26,478 & 44,230 & 21,530 & 50,000 & 145,864 \\
1997 & 0 & 14,389 & 54 & 40.0002 & 0 & 54,443 \\
Total & 8,311 & 206,676 & 142,958 & 94,203 & 130,810 & 582,958 \\
\hline
\end{tabular}

1 Excepto en vinagre o ácido acético.

2 Estimado propio en base a entrevista a empresas involucradas.

Fuente: Aduanas.

Con respecto al rubro harina, fécula y copos de papa, las exportaciones se incrementaron entre los años 1993-96. Podemos observar en las estadísticas de exportación por producto (Aduanas-Marítimo) que la línea de purés deshidratados es la más significativa, siendo los principales países importadores Rusia y Estados Unidos.

Otro rubro importante, es el del producto congelado. En 1993, el 53\% (81 t) del total de exportaciones de papa procesada correspondieron a 
este rubro. En opinión de las empresas del ramo, estas exportaciones se hicieron con el producto fresco-congelado, ya que en ese momento no habían restricciones sanitarias en los países de la Unión Europea y tampoco existían proyectos para el desarrollo en precocido-congelado. Los Países Bajos fueron los principales demandantes (61 t) seguidos de Alemania (201). En los años 1994-95 no se registran exportaciones, pero en 1996 se da un repunte con la compra de todo el producto por parte de Ecuador.

A partir de esta experiencia, los empresarios privados fueron los primeros en sondear mercados 1 e iniciar contactos con distribuidores de alimentos en mercados potenciales, participando en las ferias agropecuarias internacionales que anualmente se llevan a cabo en los países desarrollados. El resultado de dichas experiencias es que tanto en los países de la Unión Europea como en los Estados Unidos de Norteamérica existe una necesidad de abastecerse de papas que tengan: (1) buena calidad de materia prima y (2) buen rendimiento de materia seca. También se notó que, por razones fitosanitarias, la política agraria excluye la importación de papa en forma fresca de países de origen como Perú.

\section{Estrategia para la papa amarilla}

La papa amarilla es un cultivo alimenticio típico de las tierras altas de los Andes, cuya calidad depende del microclima, altura (entre los 3,200 y 4,000 m.s.n.m.), por la radiación solar y por la humedad del ambiente (no mas de $65 \%$ de humedad) donde se produce. Su consumo en fresco es altamente valorado por los habitantes del Perú, Solivia y Ecuador, apreciando sobre todo sus altos contenidos de materia seca y color, textura y sabor ideales para la preparación de papillas, purés y comidas para poblaciones en riesgo como los lactantes y las madres gestantes. Esta alta valoración alimenticia ha convertido a la papa amarilla en un cultivo alimenticio de alto valor en el mercado.

Dentro de este contexto, la Asociación de Exportadores del Perú decidió incluir en su convenio con el MSP (Microenterprise Support Project, MSP) la exportación de papa amarilla como un componente de su programa colaborativo de apoyo al pequeño productor pobre de la sierra Peruana. El convenio, que tiene como objetivo apoyar a los pequeños y micro-productores de productos con potencial comercial, decidió implementar el programa de asistencia técnica en Andahuaylas (zona de la sierra peruana con ventajas geográficas para la producción de variedades amarillas), para luego dar inicio a un programa piloto de comercialización en el mercado internacional.

${ }^{1}$ La primera exportación privada de papa amarilla seleccionada, lavada, pelada, precocida y congelada a los Estados Unidos de Norteamérica fue de la marca 'Tambo de Oro", cuyo desarrollo de producto después fue empleado como base para el producto exportado por las campañas piloto. 
El Convenio MSP había encargado un sondeo de oportunidades de mercado a un consultor; este estudio que le permitió tomar la decisión de implementar un programa de papa amarilla (elegido entre 16 productos andinos con potencial de exportación) por ser un "producto único en el mundo, debido al microclima, altura, radiación solar y humedad del medio ambiente donde se produce" (Piccha, 1994) ${ }^{1}$

Las acciones de exportación de papa amarilla se plantearon en tres etapas:

1. Entrar al mercado "cautivo" o "nicho" latino

2. Superar las barreras de precios y generar economías de escala, y

3. Penetrar al mercado anglosajón buscando la expansión del mercado.

La primera etapa, se inicia con la calificación del producto, ubicación y muestreo de los clientes potenciales y de los distribuidores, y con la implementación de una estructura productiva de exportación. El convenio consideró que el mercado internacional más próximo y con mejores opciones de ingreso era el de los Estados Unidos y el "nicho" de mercado más sensible era la demanda generada por los hábitos de consumo de la población latina, en particular la peruana. Entonces, el proyecto debería enfocarse a las ciudades con mayor concentración de población peruano/latino, como en Florida, New Jersey y New York.

En los últimos años el "mercado latino" en Estados Unidos, viene cobrando una singular importancia. Es un mercado de envergadura, ya que la población de latinos representa el $11.3 \%$ de la población total de Estados Unidos (30,500,000 de personas); viene creciendo, presentando tasas de crecimiento acumuladas de $30 \%$ entre 1991 y 1998; es un mercado muy concentrado, ya que el $75 \%$ de los latinos viven en cinco Estados. Por otro lado, la mayor parte de esta población tiene en promedio 10 años de residencia en Estados Unidos y presenta un tamaño de hogar de 3.62 personas (superior a la media americana).

En tal sentido, en la estrategia resulta importante incidir sobre la colonia peruana (como un primer paso), para ingresar al mercado latino, pues se cuenta con un público objetivo que ya conoce el producto, a través del cual se puede establecer un puente para la llegada de la papa amarilla. Existen como ejemplo, la línea de gaseosas y cervezas que han optado por esta estrategia.

En la segunda etapa, se debería buscar superar las barreras de precios, disminuyendo los precios relativos de la papa de exportación, lo que hace necesario adoptar un conjunto de acciones de desarrollo tecnológico y generación de valor agregado que reduzca los precios unitarios, hasta

${ }^{1}$ La papa amarilla peruana ha sido elegida como ganadora del premio de la FAO en Francia en 1991-92 y 1993, por su alta calidad culinaria y por su porcentaje de materia seca, que es del $34 \%$ en relación a otras papas (10-14\%). 
hacer competitivos los precios de la papa amarilla importada dentro del mercado norteamericano (Gutman y Mioti, 1996).

Capturado el mercado "cautivo" y con precios relativos competitivos, la tercera etapa radica en ingresar al mercado anglosajón más amplio, mediante acciones de promoción y educación sobre el consumo de papa amarilla, para que el consumidor norteamericano mayoritario aproveche los beneficios de calidad, sabor, textura y materia seca que ofrece la papa amarilla peruana.

\section{Campañas de exportación piloto}

Entre junio de 1995 y febrero de 1997, se llevaron a cabo las campañas de introducción del producto a los Estados de (1) Florida y (2) New Jersey-New York, facilitando la participación de empresas peruanas de agricultores, procesadores y exportadores. En estas campañas se identificaron los canales de distribución empleados por el país importador, se conocieron los mecanismos de abastecimiento a través de cadenas de supermercados y se evaluaron algunas de las características del comportamiento de los mercados "cautivo" y potencial (que han sido posteriormente desarrolladas).

Campaña Florida. Las primeras acciones se orientaron a consolidar la estructura productiva comercial que lograra la estabilidad en la producción (calidad y cantidad) y el mejoramiento de la infraestructura de procesamiento, involucrando varios agentes económicos nacionales. Paralelamente se hicieron gestiones en el mercado de Florida con el objetivo de presentar el producto final a cada cadena distribuidora identificada.

Entre junio y octubre de 1995 se hicieron tres envíos —una por vía área, dos por vía marítima-de aproximadamente 22 toneladas de papa amarilla en total. El producto llegó en la forma de papa pelada (y sin pelar), precocida y congelada en cajas de 20 y después de 12 bolsas con una libra por cada bolsa para la campaña de promoción e introducción del producto "Peruvian Golden Potatoes". Las cajas fueron distribuidas entre los puntos de venta de las cadenas de supermercados en las ciudades de Lakeland, Miami, Orlando, Quincy y Jampa . Por ejemplo, se hicieron pruebas de degustación en 23 puntos de venta de una de las cadenas de Miami. Después, se trabajó con un distribuidor en Tampa con el objetivo de alcanzar competitividad con un producto "gourmef procesado en su forma final empezando con un programa de apertura de cuatro meses de duración dirigido a un número restringido de puntos de venta. Este esfuerzo mutuo sirvió para: (1) precisar las características comerciales del producto incluyendo marca, variedad de la materia prima, forma (pelado-precocidocongelado), unidad de venta al por mayor y por menor; (2) establecer una cadena de producción-exportación-comercialización vinculando productores, procesadores, exportadores, distribuidores, minoristas, y consumidores (ver Figura 1); y (3) un es- 
quema para la estructura de "mark-ups" en la porción de dicha cadena en Florida.

Los sondeos entre distribuidores, gerentes de supermercados y representantes de cadenas sobre los pro y contra para la aceptación del producto indicaron que los supermercados están interesados en nuevos productos "gourmef, pero sólo negocian a través de sus distribuidores de confianza que presentan el producto, definen precios y volúmenes y realizan la promoción, degustación y publicidad del producto. A todos les parece importante contar con un surtido de productos que incluya, además de papa amarilla, cereales, camarones, café y cacao. Algunas cadenas de autoservicios no promueven el ingreso de nuevos productos, sólo se interesan si el producto ya está comercializado por lo menos en una cadena. Algunos distribuidores mayoristas están interesados en el producto para su línea de clientes hoteleros y restaurantes, requiriendo un stock inicial, con código de barras y presentación en cajas de mayor volumen y mejor precio. En general, el precio (US\$ 1.80/libra) les pareció un poco alto y poco competitivo. Todas las cadenas pidieron que se les garantice una oferta continua durante todo el año, lo que implica incorporar otros valles adicionales productores de papa amarilla en el Perú con diferentes calendarios de cosecha.

Campaña New Jersey-New York. Considerando el interés generado por los primeros envíos de papa amarilla, dos empresas exportadoras en el Perú se unen para firmar en mayo de 1996 un acuerdo para financiar la campaña de introducción de la papa amarilla al mercado de los estados de New Jersey y New York. En el primer trimestre de 1996 se realizó un envío de muestra de 1,000 cajas al Estado de New York en el y consistió en 850 cajas de papa amarilla pelada-precocida-congelada y 200 cajas de puré de papa amarilla. Durante la campaña de degustación- inicialmente programada con 250 puntos de venta, pero practicado sólo en 100 puntos de venta en New York y siete en New Jersey integrados a la Asociación Nacional de Supermercados, se utilizaron 309 cajas de las que posteriormente se vendieron 110 cajas; al 3 de febrero de 1997 el stock de este envío era de más de 600 cajas (600 de papa amarilla precocida congelada y 40 cajas de puré). La campaña de promoción (inicialmente programada de octubre de 1996 a febrero de 1997) incluía una campaña publicitaria con anuncios por radio, televisión y periódicos, además de la colocación de afiches y distribución de folletos y volantes. 
Figura 1. Flujo productivo comercial de la exportación de papa amarilla al Estado de Florida.

\section{Productores}

(Asociaciones por zonas productivas)

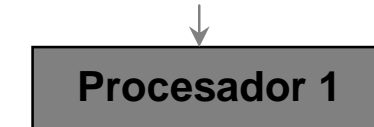

(Planta de selección y lavado)

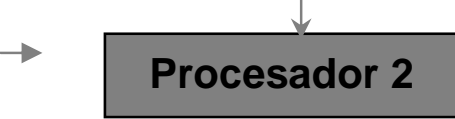

(Planta de precocido y congelado)<smiles>C1[C]2CC12</smiles>

Proveedores de Insumos

\section{Representante Comercial}

Agentes de Servicios

\section{(exportador)}

\section{País Exportador}

\section{País Importador}

\section{$\downarrow$}

\section{Cadenas de Supermercados}

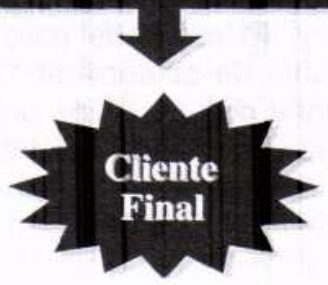

En términos comerciales, la experiencia de New York y New Jersey nos muestra que las metas de promoción no son tan fáciles de alcanzar. Por ejemplo, la empresa importadora encargada de evaluar los resultados de la campaña de promoción en New York, considera que se requieren por 
lo menos seis meses de campañas continuas de promoción para fijar las ventas mediante una mayor identificación y conocimiento de la papa amarilla. No obstante, la reacción de los consumidores fue, en general, favorable, mostrándose satisfechos por el sabor diferente y la ausencia de aditivos químicos. Más aún, aunque los compradores manifestaron que el precio les parecía alto, hubo recompra en el $45 \%$ de los 100 locales de venta. Si sólo se fijara el producto entre los consumidores peruanos de Patterson, New Jersey y estimando una compra mínima de dos libras al mes por familia (con una población objetivo de 150,000 familias), se calcula una venta mensual de 141 toneladas, lo que significa aproximadamente siete contenedores mensuales importados (cada contenedor contiene 201 aproximadamente). Este "nicho" de la demanda de los peruanos residentes, quienes además de reconocer estas características tienen el hábito de su consumo, es limitado y no genera un retorno adecuado al país exportador. Sin embargo, las degustaciones han abierto una demanda potencial que dependerá de los precios relativos. Para el consumidor potencial es necesario tener en cuenta la posibilidad de disponer de un producto exportable con precios competitivos en el mercado internacional, además de garantizar una oferta continua ampliando la infraestructura de procesamiento e integrando nuevas zonas del Perú al abastecimiento de la materia prima.

\section{Costos de la papa amarilla de exportación}

¿Cuánto cuesta procesar un kilo de papa amarilla? ¿Cómo se forma el precio final de exportación? Estos son aspectos necesarios para entender en qué medida el valor agregado por la transformación es pagado por los consumidores de los países importadores con mercados restringidos (Ordinola, 1997, 1999).

Para describir el proceso de industrialización de la papa amarilla pelada-precocidacongelada tomaremos en cuenta la última experiencia de procesamiento empleada por la planta de procesados INDICSA para la transformación y empacado de la papa amarilla de exportación enviada a New Jersey y New York (ver Figura 2). La experiencia ha permitido desarrollar los parámetros técnicos para cada una de las etapas, los cuáles ahora se encuentran a disposición de las empresas.

No existe información detallada de los costos de cada actividad. Algunos de los coeficientes técnicos varían en la medida que se optimizan las actividades. Por ejemplo, la clasificación es manual y depende de los envíos de la zona de producción, absorviendo más o menos mano de obra según la calidad del envío. Lo óptimo es que en la cosecha se haga una preclasificación lo más próxima a los estándares exigidos por la planta procesadora. Esto ahorra la mano de obra en la planta, que siempre es más cara. Lo mismo sucede con el lavado, porque dependerá de cuan limpios estén los tubérculos enviados. 
Figura 2. Flujograma del procesamiento de la papa amarilla peladaprecocida-congelada

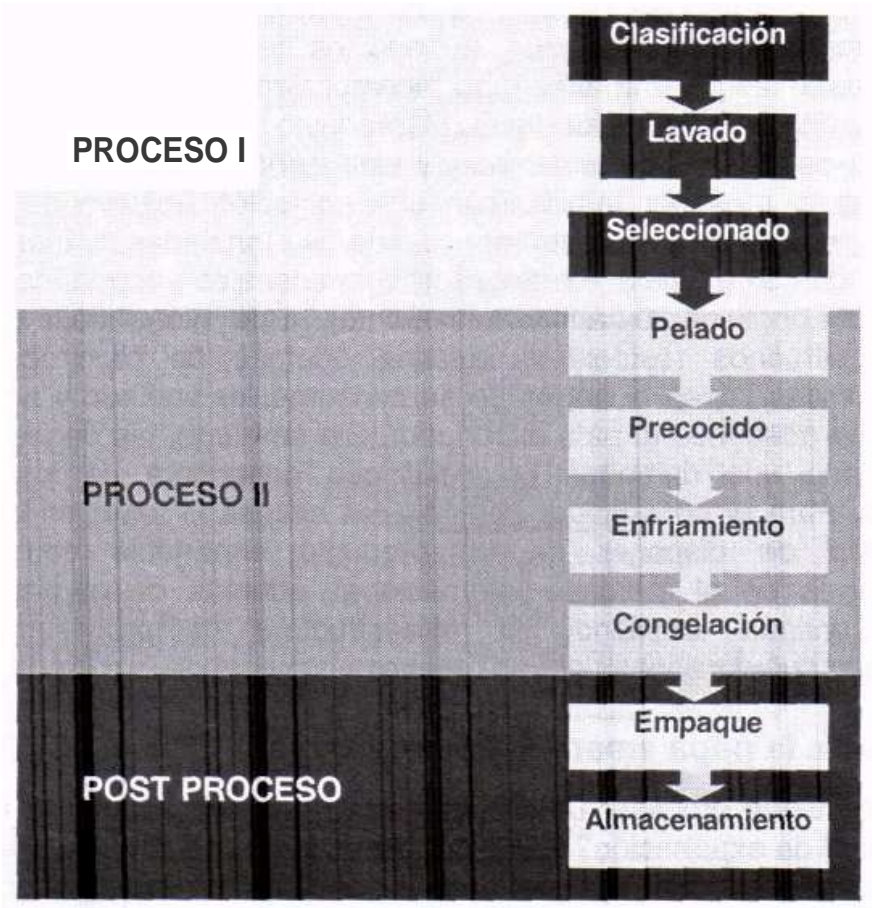

En el resto de procesos como pelado, precocido y congelación existen coeficientes técnicos más establecidos, dependiendo de la técnica y equipo empleado, aunque esta información es más difícil de obtener. Para estimar los costos sólo se tienen los precios cobrados por los servicios de las diferentes plantas que intervienen en el procesamiento industrial, desde el momento que ingresa el producto fresco a la planta hasta el traslado al almacén del distribuidor acreditado en el país importador.

La partida más importante en la formación del precio de la papa amarilla precocida y congelada puesta en puerto del Perú (precio FOB) es el servicio brindado por la planta de pelado, precocido, congelado y empaque $(46 \%$ del precio $\mathrm{FOB})$, seguido por el precio doméstico del producto fresco $(28 \%$ del precio FOB) y por los costos de certificación, aduana y trámites de exportación (22\% del precio FOB) (ver Cuadro 2). El costo del servicio por selección, lavado y clasificación (Proceso 1), incluido el $5 \%$ de merma, constituye apenas el $4 \%$ del precio FOB, porque el procesador 1 compra la papa a un precio determinado (precio 
de mercado) más un adicional por ser papa seleccionada1 de acuerdo a las exigencias requeridas por el procesador 2. Así, si se espera mayor competitividad, hay que disminuir el precio FOB en sus dos rubros principales: precio de mercado del producto fresco y costo del proceso 2 de transformación.

Un aspecto importante en la formación del precio de la papa amarilla precocida-congelada de exportación es el pago a los agentes económicos que intervienen en todo el proceso. Esta estructura puede verse en el Figura 3 , pudiendo notarse que los agentes económicos del país exportador reciben el $63 \%$ del valor de mercado del producto final, y el $37 \%$ restante (un poco más de la tercera parte del precio al consumidor en los Estados Unidos) es captado por los agentes comerciales del país importador.

Entre los agentes económicos del país exportador, los que captan el mayor porcentaje del precio final son los industriales procesadores, seguidos por los agentes comerciales y de aduana, los agricultores y los intermediarios locales. En esta experiencia piloto el pago a los agentes comerciales y de aduana es elevado debido a los pequeños volúmenes manejados hasta el momento y que podrían reducirse conforme se incrementen los mismos.

Más aún, los resultados obtenidos en una encuesta subsiguiente $(n=150+)$ sobre consumo de papa amarilla en los distritos de New York, New Jersey y Connecticut, como una forma de precisar el potencial para la introducción de este producto en la colonia peruana, mostraron que cuando se preguntó por un producto sin pelar, precocido y congelado, el $90 \%$ de los entrevistados, manifestó que la compraría con cáscara si el precio fuese menor.

Dada la aceptación por parte de los consumidores de un producto final con cáscara, se procedió a realizar ensayos para desarrollar el flujo tecnológico para procesar papa amarilla con cáscara, precocida y congelada (MSP, 1999). Los resultados de estos ensayos indicaron que las mermas se reducen considerablemente cuando se trata de producto sin pelar. Esta alternativa de procesar y comercializar la papa pre-cocida congelada con cáscara hace más atractivo el proyecto, debido a una reducción significativa en las mermas (hasta 35\%) y por lo tanto el ahorro en los costos de pelado. También se ha podido comprobar que, desde el punto de vista del consumidor, la cáscara se desprende con suma facilidad después que la papa ha sido descongelada.

\footnotetext{
${ }^{1}$ El kilo de papa amarilla seleccionada, de calidad de exportación, fue de S/. 1.17 en el mes de octubre de 1996, muy superior al precio al consumidor en el mercado limeño que estuvo alrededor de S/. 0.95.
} 
Cuadro 2. Partidas que conforman los precios FOB, CIF y al consumidor de la papa amarilla precocida congelada exportada a los Estados Unidos (US\$ por caja de 20 libras $^{1}$ )

\begin{tabular}{|l|c|}
\hline Partida & Andahuaylas \\
\hline $\begin{array}{l}\text { Costo de 13.642 kg de producto fresco (=20 lbs de producto } \\
\text { procesado) }\end{array}$ & 3 \\
\hline Costo de transporte del producto fresco & 3 \\
\hline Costo del margen de comercialización & 6 \\
\hline $\begin{array}{l}\text { Precio doméstico del producto fresco (pagado por la } \\
\text { industria) }\end{array}$ & 1 \\
\hline Costo del Proceso 1 (clasificación y lavado) & 0 \\
\hline Costo del 5\% de la merma por clasificación en planta & 10 \\
\hline $\begin{array}{l}\text { Costo del Proceso 2 (pelado, precocido, congelado, } \\
\text { embolsado, empacado) }\end{array}$ & 1 \\
\hline costos de certificación, agente aduanero y agente comercial & 18 \\
\hline costos del producto procesado (pagado por el exportador) & 4 \\
\hline $\begin{array}{l}\text { Margen neto del exportador (20\% del costo del producto } \\
\text { procesado) }\end{array}$ & 22 \\
\hline Precio FOB & 2 \\
\hline Flete del transporte naviero & 24 \\
\hline Precio CIF & 0 \\
\hline $\begin{array}{l}\text { Costos de desaduanaje y distribución del producto en los } \\
\text { Estados Unidos }\end{array}$ & 24 \\
\hline $\begin{array}{l}\text { Precio en almacén de distribuidor mayorista en Estados } \\
\text { Unidos }\end{array}$ & 5 \\
\hline Margen del distribuidor (20\%) & 30 \\
\hline Precio de venta al supermercado & 38 \\
\hline Margen del supermercado (30\%) & 2 \\
\hline Precio de venta al consumidor por caja de 20 libras & 9 \\
\hline Precio por libras de papa amarilla precocida congelada & (2) \\
\hline
\end{tabular}

1 Los costos de certificación, servicios de aduana, transporte naviero y desaduanaje están estimados considerando el envío de 1 contenedor con 1,650 cajas de 20 libras cada uno.

Tasa de cambio US $\$ 1.00=\mathrm{S} / .2 .66$. Equivalencia 1 fibra $=0.454 \mathrm{~kg}$.

* Los rendimientos promedios son de 12t/ha para Andahuaylas, basados en los últimos reportes de estas zonas de producción, con costos por ha de US\$2,562. 
Figura 3. Participación (\%) en el precio final de la papa amarilla de exportación

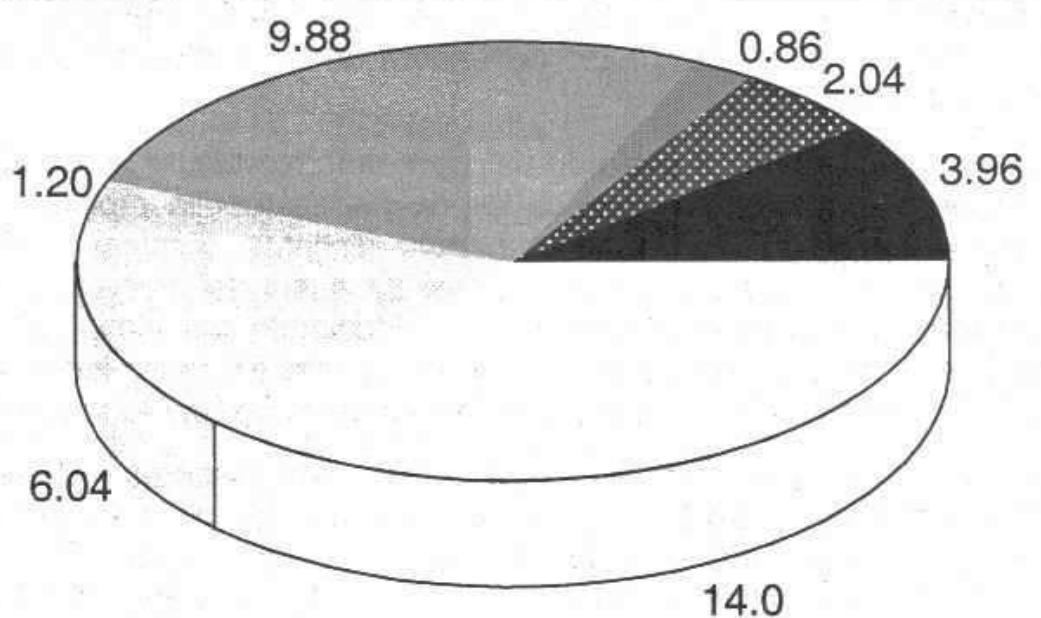
Agricultores
Intermediarios locales
Seleccionadores
Oficinas estatales ${ }^{*}$
Exportador y naviera
Imp/Distr y Superm ${ }^{\star *}$
Industriales

* Certificación, agente aduanero y comercial

* Desaduanaje, márgenes distribuidor y supermercados

\section{Conclusiones}

Con la liberalización de la economía peruana a partir de 1990, se incentiva el comercio exterior de algunos bienes y servicios. Productos agrícolas como ajos, cebolla, espárrago, frutas, fibras y otros comienzan a orientarse al mercado internacional. En este contexto, surgió un interés en el mercado de exportación potencial por productos procesados de papa. Este trabajo documenta las experiencias de intentar penetrar el mercado de los Estados Unidos, particularmente los estados de Florida, New Jersey y New York con productos procesados de papa amarilla.

Los consumidores latino/peruano en los Estados Unidos mostraron bastante aceptación del producto, sobresaliendo, además de la calidad y el sabor, la facilidad de preparación de las papas precocidas congeladas. No obstante, las ventajas comparativas de la papa amarilla como calidad nutritiva requieren desarrollar un mercado más amplio en la búsqueda de precios competitivos. En todas las experiencias de introducción, una de 
las limitantes del consumo es el elevado precio relativo en comparación con las papas producidas internamente o importadas de otros países.

No es necesario que las papas amarillas se equiparen al precio internacional, pero sí es importante que no exista un margen tan amplio. El poder disminuir este precio dependerá de los costos de producción y procesamiento.

En cuanto al procesamiento, es necesario continuar investigando la respuesta de diferentes variedades de papa amarilla producidas en el Perú, y también continuar probando distintas técnicas de pelado, precocido y congelado que mejoren la eficiencia del proceso y por ende optimicen los costos, especialmente reduciendo las elevadas mermas actuales. Las pruebas realizadas con producto sin pelar indican que es posible manejar esta variable, reduciendo mermas y por lo tanto costos.

La experiencia ya desarrollada con distintos exportadores y distribuidoras debe servir para interesar a nuevos inversionistas o socios potenciales, que permitan enfrentar una inversión conjunta que se oriente a desarrollar el nivel de rentabilidad y beneficios. Un aspecto que ha sido necesario cubrir para interesar a inversionistas y socios potenciales es el estudio de la demanda. En tal sentido, se ha avanzado en conocer el comportamiento de la demanda y sobre esta base es posible trabajar programas de promoción de mayor envergadura.

La apertura de mercados es un proceso complejo y laborioso, donde intervienen varios agentes económicos tanto del país exportador como del importador, y se requiere negociar todos estos intereses en función de un solo objetivo. Es necesario, entonces, clarificar el objetivo y continuar con el programa de apoyo definiendo claramente los roles y compromisos de los promotores, exportadores e importadores en función de planes de mediano plazo y no de resultados de corto plazo.

Los elevados costos de apertura de mercado para un producto de exportación, como es el caso de la papa amarilla precocida congelada, requieren de la participación de más instituciones promotoras, donde el Estado debe jugar un rol preponderante. Ningún empresario exportador o importador se compromete con productos nuevos, casi siempre invierten en productos que están siendo comercializados localmente. Por lo tanto, previo un estudio de las ventajas comparativas y del aporte en la balanza comercial de un país, el Estado debe comprometerse con la apertura de mercados para sus productos con mayor potencial. En el caso de la papa amarilla precocida congelada existen evidencias de dicha potencialidad que deben seguir sondeándose.

Un programa de exportación de papa amarilla procesada beneficiaría directamente a los pequeños agricultores de los Andes, generando un mercado para sus excedentes de producción e incrementando de ese modo la rentabilidad del producto al diversificar sus destinos. La estacionalidad de los precios domésticos ya no afectaría tanto al 
productor que, además de los riesgos de mercado, tiene que enfrentar riesgos climáticos que alteran su productividad. Conforme avance el programa se debe buscar la sostenibilidad de la producción avanzando hacia la especialización del agricultor como ofertante de un producto que cumpla con los requisitos de procesamiento y calidad de exportación.

\section{Bibliografía}

Gutman, G.E. y L.E. Mioti. 1996. Exportaciones agroindustriales de América Latina y El Caribe. Especialización, competitividad y oportunidades comerciales en los mercados de la OCDE. Lima, CEPAL-FAO.

Microenterprise Support Project (MSP). 1999. Determinación de Parámetros para el procesamiento de papa amarilla con cascara. Convenio MSP/ADEX-USAID, Lima.

Ordinola, M. 1997. Articulación de la pequeña agricultura con mercados de mayor exigencia: El caso de la papa amarilla. Documento preparado para el Seminario Permanente de Investigación Agraria SEPIA, Lima.

Ordinola, M. 1999.Estudio técnico económico de productos procesados de papa. Informe de consultoría a CONTRADROGAS (4 Volúmenes: Resumen Ejecutivo, El Mercado de la Papa, La Oferta de Huánuco, Ingeniería del Proyecto-Análisis Económico Financiero). Lima.

Piocha, D. 1994. World situation and export market Opportunities for 16 Andean crops. Mimeo, Lima, ADEX/AID.

Scott, G. 1986. Mercados, mitos e intermediarios: La comercialización de la papa en la zona central del Perú. - 2a. ed. - Lima: Centro de Investigación de la Universidad del Pacífico.

. 1998. "Los fast foods aumentan demanda de la papa procesada".

En: Síntesis. El Diario de Negocios del Perú. Publicado el 24/02/98. 